\title{
ACTAS DA CONGREGAÇÃO DOS LENTES DA ACADEMIA DE DIREITO DE SÃO PAULO
}

\author{
Álvaro Villaça Azevedo \\ Diretor da Faculdade de Direito da Universidade de São Paulo
}

Actas

A idéia da criação dos cursos jurídicos no Brasil foi em 1822, com a Independência do Brasil, uma vez que até então os brasileiros iam estudar Direito em Coimbra, Portugal. Em 1827, por meio do Decreto Imperial de 11 de agosto, doís cursos jurídicos foram criados; um em São Paulo, outro em Olinda.

A nossa Academia foi inaugurada em $1^{\circ}$ de março de 1828 , no Convento de São Francisco. O prédio antigo foi, por sua vez, demolido em 1930. E, em 1934, novo prédio foi inaugurado, incorporando-se à Universidade de São Paulo, pelo decreto federal de 10 de agosto. Cumpre salientar que, desde sua criação, a Faculdade de Direito da Universidade de São Paulo pertenceu ao governo central, monárquico e, depois, republicano.

No atual Governo, pelo então ministro da Justiça, Nelson Jobim, firmou-se um convênio com a Faculdade de Direito, em 09 de agosto de 1996, para que fossem editadas as Actas de sua Congregação, do período imperial, por meio de quatro volumes, concretizando a idéia do pesquisador, doutor Aurélio Wander Bastos.

Esse sonho tornou-se realidade com a publicação dessa obra pela Xerox do Brasil (edição fac-similar), sob a coordenação do doutor Heitor Chagas.

As Actas contêm discussões dos mestres das Arcadas, não-só de caráter político, mas jurídico; como contêm verdadeiras programações de ensino jurídico que foram fonte da educação nacional na área do Direito, como paradigmas, por meio de seus programas seguidos pelas instituições superiores de ensino. 


\title{
Tradição
}

\begin{abstract}
Passaram pelos bancos das Arcadas eminentes personalidades: presidentes da República, governadores, poetas, estadistas, jurisconsultos, parlamentares, literatos, oradores, diplomatas, jornalistas e empresários. Além disso, nossas Arcadas sentiram as vibrações patrióticas na Revolução Constitucionalista de 1932, tendo sido sempre um centro de resistência democrática aos regimes ditatoriais. As Arcadas participaram de movimentos nacionais notáveis, dos quais resultou a Carta aos Brasileiros, de 08 de agosto de 1977. de autoria do emérito professor doutor Goffredo da Silva Telles Júnior, trazendo ao País a volta ao Estado de Direito.
\end{abstract}

Em 11 de agosto de 1996, inauguramos o período de Comemoração dos 170 Anos da Academia das Arcadas, que culminou no dia 11 de agosto do ano de 1997. Foram semanas de comemorações, inclusive de 150 anos do inesquecível poeta Castro Alves.

O primeiro ato dessas comemorações foi marcado pela solenidade de entrega do primeiro volume das Actas. Uma homenagem à Faculdade de Direito da Universidade de São Paulo pelo Ministério da Justiça, representado por seu então ministro Nelson Jobim, que assinou convênio com nossa Academia, para a edição das Actas de sua Congregação, no período imperial.

\section{Ediç̃̃o das Actas}

Foram reproduzidos, em edição fac-similar, 25 exemplares históricos destinados: ao presidente da República, Fernando Henrique Cardoso; ao vicepresidente da República, Marco Antonio Maciel; ao presidente da Comissão de Relações Exteriores do Senado Federal, José Sarney; ao ministro da Justiça, Nelson Jobim; ao presidente do Supremo Tribunal Federal, Sepúlveda Pertence; ao presidente do Superior Tribunal de Justiça, Romildo Bueno de Souza; ao ministro da Educação e do Desporto, Paulo Renato de Souza; ao procurador-geral da República, Geraldo Brindeiro; ao presidente do Conselho Federal da Ordem dos Advogados do Brasil, Ernando Uchôa Lima; ao ex-presidente do Conselho Federal da Ordem dos Advogados do Brasil, hoje senador Bernardo Cabral; ao presidente da Câmara dos Deputados, Michel Temer̈; ao presidente da Xerox do Brasil, Carlos Augusto Salles; ao governador do Estado de São Paulo, Mário Covas; ao presidente da Assembléia 
Legislativa, Paulo Kobayashi; ao ex-prefeito do Município de São Paulo, Paulo Salim Maluf; ao prefeito do Município de São Paulo, Celso Pitta do Nascimento; ao presidente do Tribunal Regional Federal $3^{\text {a }}$ Região, Jorge Tadeu Flaquer Scartezzini; ao Diretor da Faculdade de Direito da Universidade de São Paulo, Álvaro Villaça Azevedo; ao presidente do Tribunal de Justiça de São Paulo, Yussef Said Cahali; ao Reitor da Universidade de São Paulo, Jacques Marcovitch; ao exreitor da Universidade de São Paulo, Flávio Fava de Moraes; ao presidente da Ordem dos Advogados do Brasil, Guido Antonio Andrade; ao procurador-geral de Justiça de São Paulo, Luís Antonio Guimarães Marrey; ao Centro Acadêmico XI de Agosto da Faculdade de Direito da Universidade de São Paulo; ao Serviço de Biblioteca e Documentação da Faculdade de Direito da Universidade de São Paulo.

\section{Lançamento dos volumes das Actas}

O primeiro volume foi lançado na sala da Congregação da Faculdade de Direito, com a presença do Magnífico Reitor, professor Flávio Fava de Moraes, do senhor ministro do Supremo Tribunal Federal, Sydney Sanches, do senhor doutor Heitor Chagas, diretor da Xerox do Brasil, dos senhores doutores professor Aurélio Wander Chaves Bastos e Cláudio Salvador Lembo.

O segundo volume foi apresentado e lançado na biblioteca do Ministério da Justiça, em Brasília, com a presença do vice-presidente da República, Marco Maciel, do ministro da Justiça, Nelson Jobim, do presidente do Supremo Tribunal Federal, ministro Sepúlveda Pertence, do presidente do Superior Tribunal de Justiça, ministro Romildo de Souza, e do doutor Heitor Chagas, da Xerox do Brasil.

O terceiro volume foi apresentado no Conselho Federal da Ordem dos Advogados do Brasil, em Brasília, onde nasceu a idéia de melhorar os cursos jurídicos brasileiros pelo seu então presidente, e hoje senador da República, Bernardo Cabral. Estavam presentes, nessa oportunidade, o presidente do Conselho da Ordem dos Advogados do Brasil, Ernando Uchòa Lima, o presidente da Câmara dos Deputados, o deputado Michel Temer, e o ministro da Justiça, Iris Resende.

O quarto volume das Actas foi lançado na sala da Congregação de nossa Faculdade de Direito, sempre com o apoio que nos foi dado pelo Ministério da Justiça e pela Xerox do Brasil, que, com seus equipamentos fantásticos, tornou possível realizar o sonho tão-almejado, por nós, que respeitamos nossa velha, mas sempre nova, entusiasta, idealista e corajosa Academia. 


\section{APRESENTAÇÃO}

A divulgação das Actas da Congregação dos Lentes da Academia de Direito de São Paulo, instalada após criação, pela Lei de 11 de agosto de 1827, de "dous cursos de Sciencias Jurídicas e Sociaes, um na cidade de São Paulo e outro na de Olinda", é um significativo ato para a recuperação da história e dos destinos da Faculdade de Direito da Universidade de São Paulo e das elites intelectuais, políticas e administrativas do Estado de São Paulo e do Brasil.

O professor e pesquisador, dr. Aurélio Wander Chaves Bastos, em pesquisa desenvolvida nos arquivos da Faculdade, identificou e reconheceu, nesses documentos, fonte importante para o ensino, e para a pesquisa jurídica e histórica no Brasil. Em decorrência desse lavor, nasceu a idéia de compilação dos textos documentais e de sua divulgação "fac-símile" como especial forma de facilitar a consulta e resguardar os originais, assim como de levar ao conhecimento das autoridades públicas e acadêmicas o seu relevante conteúdo.

Analisando a correspondência, entendemos que esses originais das Actas, entre os anos de 1837 e 1889, mereciam não apenas uma edição restrita, mas, também, uma edição gráfica, como obra comemorativa do início das festividades dos 170 anos da criação dos Cursos Jurídicos no Brasil.

Este trabalho de impressão "fac-símile" em quatro volumes, tornou-se possível com o efetivo apoio da Xerox do Brasil, especialmente de seu presidente, dr. Carlos Salles, e de seu diretor, dr. Heitor Chagas, que reconheceram a importância dos documentos para o ensino jurídico e para a História de São Paulo e do Brasil, com utilização de apurada e moderna tecnologia.

Por meio desta edição "fac-símile" poderão ser conhecidos os principais atos praticados pela Congregação dos Lentes da Academia (hoje Faculdade de Direito da Universidade de São Paulo) e pelos seus diretores históricos, bem como todos os atos acadêmicos que influenciaram o ensino jurídico, a participação de seus professores em questões políticas e acadêmicas imperiais e os seus programas e currículos à época.

Os originais das Actas tiveram o privilégio de serem editados pelo Departamento de Imprensa Nacional por solicitação do ministro da Justiça, Nelson Jobim, como especial forma de ampliar seu acesso aos estudantes, professores e pesquisadores brasileiros, e a profissionais do Direito. 
Esta edição constitui-se em verdadeira relíquia a ser integrada aos documentos fundamentais que hão de revelar a história do ensino do Direito no. Brasil.

Finalmente, temos absoluta conviç̧ão de que a edição "fac-símile" destas Actas, e sua subseqüente publicação, confirmará a importância dos estudos jurídicos no Brasil e sua influência e significado para a formação da nacionalidade brasileira.

TERMO DE CONVÊNIO QUE ENTRE SI CELEBRAM A UNIÃO FEDERAL, POR INTERMÉDIO DO MINISTÉRIO DA JUSTIÇA, COM A INTERVENIÊNCIA DA SECRETARIA DE DIREITO ECONÔMICO MINISTÉRIO DA JUSTIÇA, E A UNIVERSIDADE DE SÃO PAULO, COM A INTERVENIÊNCIA DA FACULDADE DE DIREITO, PARA OS FINS QUE ESPECIFICA.

\section{CLÁUSULA PRIMEIRA DO OBJETO}

O presente Convênio tem por objeto a preparação técnica e posterior publicação da coletânea histórica dos manuscritos das "ACTAS DA CONGREGAÇÃO DA ACADEMIA DE DIREITO DE SÃO PAULO" produzidas no período de 1837 a 1889 .

\section{CLÁUSULA SEGUNDA DAS OBRIGAÇÕES}

\section{DO MINISTÉRIO}

a) preparação técnica e publicação das Actas;

b) destinar recursos financeiros necessários à publicação das Actas;

d) promover esforços destinados ao estudo analítico da coletânea, coordenadamente com a Faculdade de Direito de São Paulo. 


\section{DA FACULDADE}

a) ceder os originais manuscritos das Actas da Congregação da Academia de Direito de São Paulo, produzidas entre os anos de 1837 a 1889 , na forma "fac-símile";

b) entregar os originais em "fac-símile" na data da assinatura deste Convênio.

\section{SUBCLÁUSULA ÚNICA}

Os recursos humanos, materiais e financeiros destinados à preparação técnica e à publicação ficarão a cargo da Secretaria de Direito Econômico do Ministério da Justiça.

\section{CLÁUSULA TERCEIRA - DOS RECURSOS ORÇAMENTÁRIOS}

Os recursos orçamentários necessários à consecução do Objeto do presente Convênio correrá à conta do Projeto Código 03009.0042.3416.0001, natureza da Despesa 3490.39 - Serviço de Terceiras Pessoas Jurídicas.

\section{CLÁUSULA QUARTA DA EDIÇÃO}

A publicação das Actas será realizada pela Imprensa Nacional, observado o disposto na Lei n. 8.666/93.

\section{CLÁUSULA QUINTA - DO QUANTITATIVO}

Serão publicados, inicialmente, hum mil e quinhentos volumes, que serão distribuídos, gratuitamente, para as Bibliotecas das Faculdades de Direito, Órgãos Públicos e Centros de Pesquisas.

\section{CLÁUSULA SEXTA DA VIGÊJNIA}

O presente Convênio terá sua vigência a partir da data de sua assinatura por um período de vinte e quatro meses, podendo ser prorrogado e/ou alterado através de termo aditivo mediante expressa manifestação das Partes. 


\section{CLÁUSULA SÉTIMA DA EXTINÇÃO}

Este Convênio poderá ser resolvido, automaticamente, por inexecução total ou parcial de qualquer de suas cláusulas ou condições, ou pela superveniência de norma legal ou evento que o torne material ou formalmente inexeqüível.

\section{CLÁUSULA OITAVA DAS DÚVIDAS}

As dúvidas suscitadas na execução deste Convênio serão dirimidas em comum acordo pelas Partes.

\section{CLÁUSULA NONA DA PUBLICAÇÃO}

A publicação do presente Instrumento será efetuada em extrato no Diário Oficial da União, no prazo de vinte dias a contar da data de sua assinatura, corrente à conta do Ministério a respectiva despesa.

\section{CLÁUSULA DÉCIMA DO FORO}

Para dirimir conflitos porventura decorrentes deste Convênio, fica eleito o foro do Distrito Federal com renúncia expressa de qualquer outro, por mais privilegiado que seja.

E, para validade do que pelas partes foi pactuado, firma-se este Instrumento em duas vias de igual teor e forma, na presença das testemunhas abaixo assinadas, para que surta seus efeitos jurídicos e legais efeitos.

Brasília-DF, 09 de agosto de 1996

NELSON A. JOBIM Ministro da Justiça

ÁLVARO VILLAÇA AZEVEDO

Diretor da Faculdade de Direito da USP
FLÁVIO FAVA DE MORAES

Reitor da Universidade de São Paulo

AURÉLIO WANDER CHAVES BASTOS

Secretário de Direito Econômico 